\title{
ZnO nanowire-coated hydrophobic surfaces for various biomedical applications
}

\author{
AMITENDER SINGH and SARAVJEET SINGH* \\ Department of Biomedical Engineering, D.C.R. University of Science \& Technology, Sonipat 131039, India \\ *Author for correspondence (saravjeet.bme@dcrustm.org)
}

MS received 3 April 2017; accepted 17 November 2017; published online 10 July 2018

\begin{abstract}
Recently, hydrophobic surfaces are finding many applications in the field of biomedical. This study reports the simple and facile method of hydrophobization of various surfaces like glass, semiconductor and polymer, etc. used in biomedical field by using durable and water-resistant $\mathrm{ZnO}$ nanowires coating. The change in contact angle of ethylenediaminetetraacetic acid (EDTA) anticoagulated whole blood (EDTA-WB) on various substrates like; glass, quartz, Si and polydimethylsiloxane (PDMS) before and after $\mathrm{ZnO}$ nanowires coating is reported. It was observed that the different type of substrates show great variation in contact angle of EDTA-WB, before and after ZnO nanowires coating. The substrates which are generally hydrophilic for EDTA-WB become hydrophobic after ZnO nanowires coating. This surface-coating technique can be utilized in various biomedical applications, for example, in medical devices and surgical equipments coating, orthopaedic dressings, in-vivo implants and corrosion-resistance surfaces.
\end{abstract}

Keywords. Hydrophobization; anticoagulated; EDTA; whole blood; nanowires.

\section{Introduction}

Hydrophobic surfaces are widely used in biomedical applications like orthopaedic dressings, in-vivo implants and corrosion-resistance surfaces. Scientists and researchers from various disciplines are disseminating their knowledge for the rapid development of hydrophobic biomaterials with antibacterial activity. Various biomaterials like polyurethane, polydimethylsiloxane (PDMS), Teflon, silicone rubber, poly(methyl methacrylate) (PMMA), stainless steel and titanium were used in cochlear implants, heart valves, stents, dental implants, bone plates, joint replacement, skin repair, vascular grafts, catheters, tubing, drug delivery and wound-dressing application [1]. Various nanomaterials used for hydrophobic coatings are manganese oxide polystyrene $\left(\mathrm{MnO}_{2} / \mathrm{PS}\right)$, zinc oxide polystyrene ( $\mathrm{ZnO} / \mathrm{PS})$, precipitated calcium carbonate [2], carbon nanotube structures, etc. Recently, the semiconductor material coatings attract researchers' attention at the most. The biocompatibility, non-toxicity, antibacterial and antimicrobial properties, photo-catalytic activity and physiochemical stability of semiconductor materials make their coatings most advantageous in biomedical applications [3]. Among the semiconductor materials, $\mathrm{ZnO}$ is biosafe and biocompatible material [4] and widely used in biomedical applications [5,6]. Li et al [7] showed that $\mathrm{ZnO}$ nanowires are completely biosafe and biocompatibility when used in concentrations $<100 \mu \mathrm{g} \mathrm{ml}^{-1}$. Due to the extreme repellence and bacterial resistance of $\mathrm{ZnO}$ nanostructure-based hydrophobic coatings; there is more scope and wider potential for application uses in medical equipments and surgical tools. The primary purpose of hydrophobic coating is to repel water from the material surfaces and acts as a sealant, so that water cannot penetrate through the surface. Nanostructures surface coating is an additional way to modify surfaces of both metals and polymers in an effort to increase hydrophobicity. This technique do not involve direct attachment of chemical groups or surface chemical alterations as the way conventional chemical modification techniques do, but still makes the surfaces more hydrophobic.

The coating technique must consider the material properties as the response of the coated surface to the fluid may decide the performance of the finished device or material. The oxide nanostructures-based coating is more durable than other gel-based coatings [7]. Carbon nanotubes coating is more expensive and the coating method is complex and difficult as compared to $\mathrm{ZnO}$ nanowires coating. Hence, the $\mathrm{ZnO}$ nanostructures-based coating remains the most economic and efficient option of coating. If the $\mathrm{ZnO}$ nanostructures are hydrophobic in nature then, it is very useful in avoiding the health risk by some of the bacteria like Legionella, which is typically found in water and can cause special type of pneumonia known as Legionnaries disease. Because, if the material surface is hydrophilic, the bacteria present in water may adhere to the biomaterial, resulting in biofilm formation, which may cause pathogenesis [8-10]. For achieving antibacterial activity, many surface modification techniques were employed by the scientists and bioengineers for modification of surface physiochemical properties like silver coating and calcitite hydroxyapatite plasma-sprayed coating, 
(a)

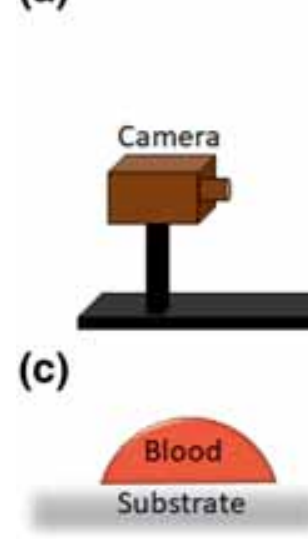

(i)
Micro-pipette
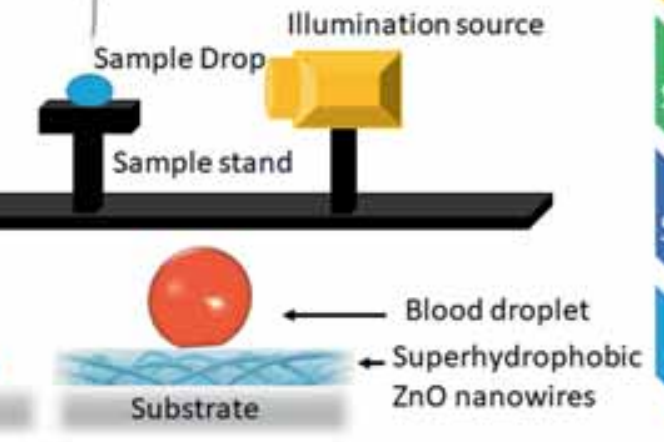

(ii) (b)

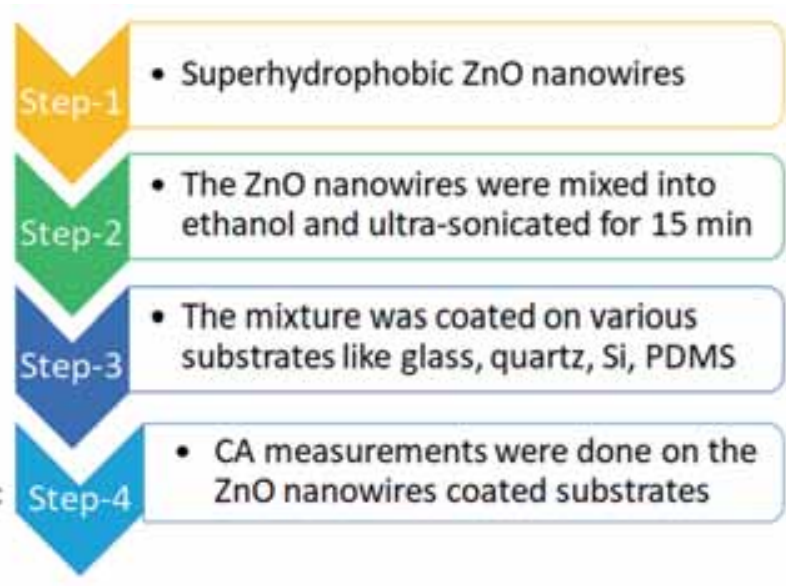

- The $\mathrm{ZnO}$ nanowires were mixed into ethanol and ultra-sonicated for $15 \mathrm{~min}$

The mixture was coated on various substrates like glass, quartz, Si, PDMS

CA measurements were done on the ZnO nanowires coated substrates

Figure 1. (a) Schematic diagram of the contact angle measurement setup, (b) graphical representation of the steps followed in the coating of $\mathrm{ZnO}$ nanowires on various substrates, and (c) schematic representation of the variation in contact angle on the outer surface of the substrate (i) before $\mathrm{ZnO}$ nanowires coating and (ii) after $\mathrm{ZnO}$ nanowires coating for decreased blood wettability.

antibiotic impregnation into polymer matrix, etc. [11-13]. These techniques include harsh chemical treatment and are complex antibacterial coating methods. $\mathrm{ZnO}$ deposition by using drop-coating method is very helpful to avoid the barrier of low heat resistance of many biomaterials mainly polymers. A smart approach is required to make the surface hydrophobic with antibacterial property in a simple and cost-effective manner. If a hydrophobic semiconductor coating is available for biomaterials or biodevices then, it can serve dual purpose as it can make the biomaterial surfacehydrophobic as well as bacteria-resistant. These requirements stimulate an extensive research in the direction to prepare antibacterial hydrophobic semiconductor coating for biomaterials.

Here, our main focus is to develop a semiconductor material-based hydrophobic coating for biomaterials. Our works include utilization of hydrophobic $\mathrm{ZnO}$ nanowires for hydrophobic coating on various substrates like; glass, quartz, Si and PDMS. After $\mathrm{ZnO}$ nanowires coating, the substrates become hydrophobic for EDTA-WB. The contact angle (CA) measurements show a drastic change in surfacewetting behaviour, before and after $\mathrm{ZnO}$ nanowires coating, for EDTA-WB on various substrates. The observed results indicate that hydrophobization of various substrates is possible by $\mathrm{ZnO}$ nanowires coating, which can be utilized for various biomedical applications.

\section{Experimental}

\subsection{CA measurement setup}

The CA measurements were done by using commercially available image capturing setup by using sessile drop method on various substrates before and after $\mathrm{ZnO}$ nanowires coating. Figure 1a shows the schematic diagram of the experimental setup used for the measurement. A high definition camera is used for capturing the images. The sample volume of drop is about $5 \mu \mathrm{l}$ for each measurement. To minimize the error in measurements, five sets of measurements were taken on a sample and then, the average value was used for analysis. The available $\mathrm{ZnO}$ nanowires show hydrophilic nature. We have placed the nanowires in dark for 40 days to make them as superhydrophobic. The superhydrophobic $\mathrm{ZnO}$ nanowires coating on various substrates were done by using drop-coating method.

\subsection{ZnO nanowires coating process and hydrophobization}

The process of coating of the superhydrophobic $\mathrm{ZnO}$ nanowires on the substrates is shown in figure $1 \mathrm{~b}$. $\mathrm{ZnO}$ nanowires coating was done by mixing the $\mathrm{ZnO}$ nanowires with alcohol (ethanol) and then, ultrasonicating it for $15 \mathrm{~min}$ for better mixing. Then, the mixture is drop-coated on various substrates. Different types of sample substrates are prepared by coating the $\mathrm{ZnO}$ nanowires like $\mathrm{Si}$, PDMS, glass and quartz. CA is the measure of wettability and a useful gauge to determine the interactions of biomaterials with the surrounding biological environment with water-like physiology [14]. The hydrophobization of various substrates after $\mathrm{ZnO}$ nanowires coating increases the CA of EDTA-WB on the substrates, there by making the substrates hydrophobic for decreased blood wettability. Figure 1c shows the diagram of proposed method where the outer surface of the substrates are made hydrophobic by $\mathrm{ZnO}$ nanowires coating, which increases the $\mathrm{CA}$ and hence, reduces water wetting of the surface. 

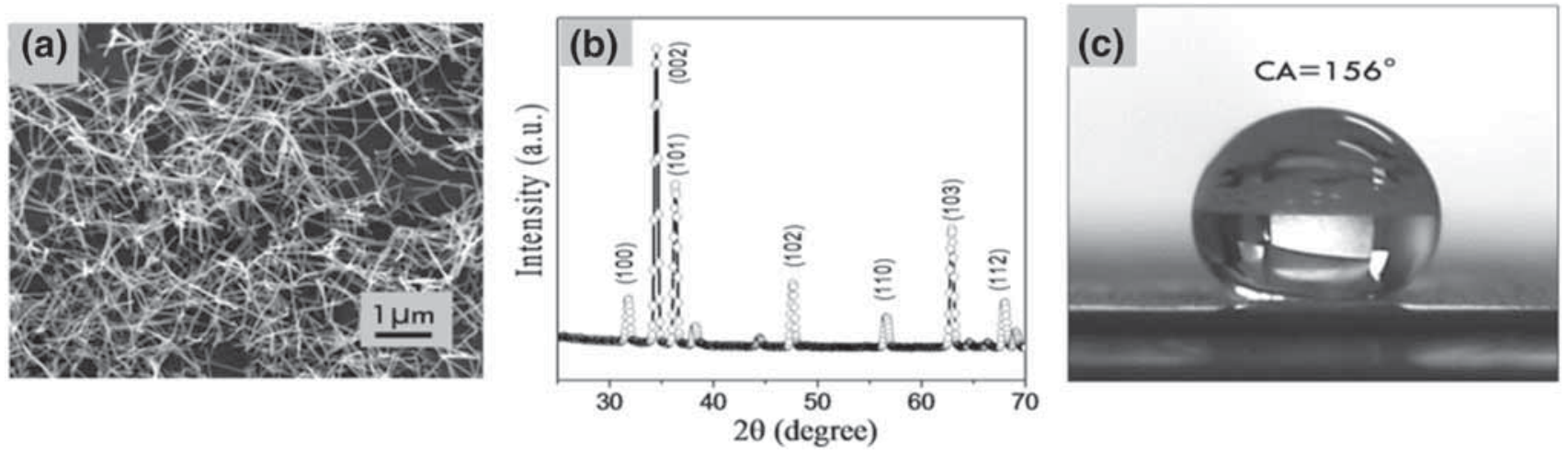

Figure 2. (a) SEM, (b) XRD and (c) water-contact angle images of the $\mathrm{ZnO}$ nanowires-coated on Si substrate.

Table 1. Concentrations of various blood components in the blood sample.

\begin{tabular}{lc}
\hline Component & Concentration \\
\hline WBC & $9.04 \times 10^{9} \mathrm{l}^{-1}$ \\
LYM & $3.46 \times 10^{9} \mathrm{l}^{-1}$ \\
GRA & $5.11 \times 10^{9} \mathrm{l}^{-1}$ \\
RBC & $5.87 \times 10^{12} \mathrm{l}^{-1}$ \\
HGB & $14.2 \mathrm{~g} \mathrm{dl}^{-1}$ \\
HCT & $44.80 \%$ \\
PLT & $2.48 \times 10^{9} \mathrm{l}^{-1}$ \\
\hline
\end{tabular}

\section{Results and discussion}

\subsection{Sample characterization}

The SEM image of the $\mathrm{ZnO}$ dispersed on $\mathrm{Si}$ substrate is shown in figure 2a. The SEM image clearly reveals that the $\mathrm{ZnO}$ material has nanowires like morphology with average diameter of about $70 \mathrm{~nm}$. The XRD spectra of the material illustrate that the $\mathrm{ZnO}$ has wurtzite phase (figure $2 \mathrm{~b}$ ). The superhydrophobic $\mathrm{ZnO}$ nanowires dispersed on $\mathrm{Si}$ substrate shows water contact angle of about $156^{\circ}$ as shown in figure $2 \mathrm{c}$.

\subsection{Blood cell counter}

The concentration of various blood cells in the fresh blood sample (used for CA) as measured by the automatic blood cell counter is shown in table 1 . For measurements of the concentration of various blood cells in the blood sample, Yark Abacus III automatic blood cell counter was used.

\subsection{CA measurement}

Here, to analyse the blood interaction with different surfaces, we have conducted the sessile droplet method-based CA measurements on various surfaces with a $5 \mu \mathrm{l}$ blood droplet. The images of blood CA on various sample substrates before and after $\mathrm{ZnO}$ nanowires coating is shown in figure $3 \mathrm{a}-\mathrm{d}$. It is found that after $\mathrm{ZnO}$ nanowires coating, the blood $\mathrm{CA}$ on quartz substrate increases from 54.6 to $96.4^{\circ}$. For glass substrate, the blood CA value increases from 28.5 to $145.7^{\circ}$. For Si substrate, it increases from 62 to $138.8^{\circ}$ and for PDMS substrate, the blood CA value increases from 81.4 to $131.6^{\circ}$. The observed results revealed that the various types of substrates, which are initially hydrophilic to blood become hydrophobic after $\mathrm{ZnO}$ nanowires coating. It indicates that the hydrophobization of various substrates is possible by $\mathrm{ZnO}$ nanowires coating. Hydrophobic surfaces are those on which the water drop makes a contact angle (CA) greater than $90^{\circ}$ and if it is above $150^{\circ}$, the surfaces are known to be superhydrophobic surfaces. Superhydrophobic surfaces are very difficult to wet and the surface-water interactions are very less [15]. Some of the naturally occurring superhydrophobic surfaces are lotus leaf, water strider, butterfly wings, etc.

The wettability on $\mathrm{ZnO}$ surfaces can be explained by the Young's, Wenzel or Cassier-Baxter models as shown in figure 4. The Young's contact angle, $\theta$ for the liquid drop on a smooth solid surface, is determined by the surface-free energies involved [16],

$\cos \theta=\left(\gamma_{\mathrm{sv}}-\gamma_{\mathrm{sl}}\right) \gamma_{\mathrm{lv}}$,

where $\gamma_{\mathrm{sl}}, \gamma_{\mathrm{sv}}$ and $\gamma_{\mathrm{lv}}$ are the solid/liquid, solid/vapour and liquid/vapour tensions, respectively.

The apparent contact angle $\theta_{\mathrm{a}}$ for a rough surface is given by the Wenzel model [17],

$$
\cos \theta_{\mathrm{a}}=r \cdot \cos \theta_{\mathrm{b}},
$$

where $\theta_{\mathrm{b}}$ is a contact angle on a smooth surface and $r$ is a surface roughness factor.

The Cassier-Baxter model is applicable once the contact is lost. It can be described by the Cassier equation [18],

$$
\cos \theta_{\mathrm{r}}=f_{1} \cos \theta-f_{2},
$$

where $\theta$ and $\theta_{\mathrm{r}}$ are the contact angles for smooth and rough surfaces, respectively; $f_{1}$ and $f_{2}$ are the fractional interfacial areas of $\mathrm{ZnO}$ and the air trapped between the surface and a water droplet, respectively. 


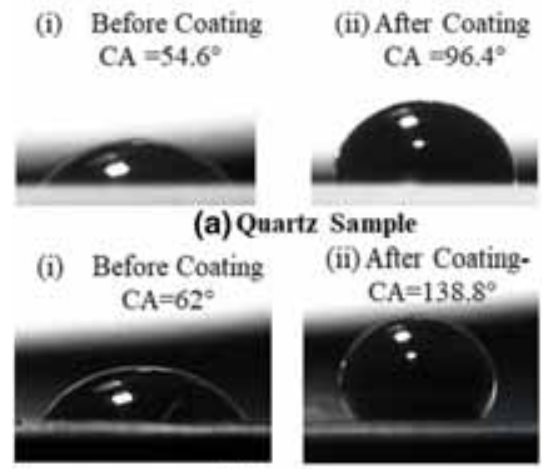

(c) Silicon Sample

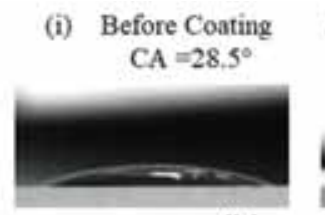

(ii) After Coating $\mathrm{CA}=145.7^{\circ}$

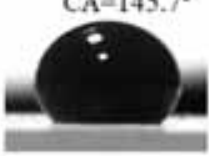

(b) Glass Sample

(i) Before Coating $\mathrm{CA}=81.4^{\circ}$

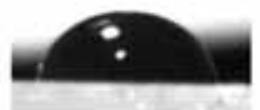

(ii) After Coating $\mathrm{CA}=131.6^{\circ}$

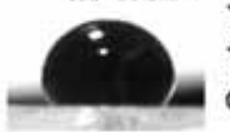

(d) PDMS Sample

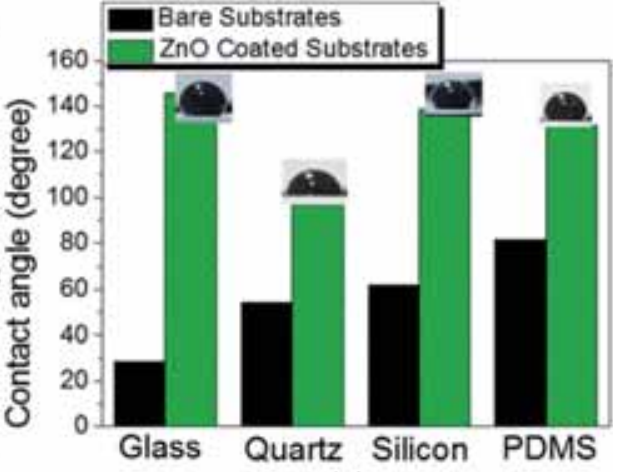

(e)

Figure 3. Contact angle on various substrates before and after ZnO nanowires coating: (a) quartz, (b) glass, (c) silicon, (d) PDMS samples and (e) contact angle of EDTA-WB on various substrates before and after ZnO nanowires coating.

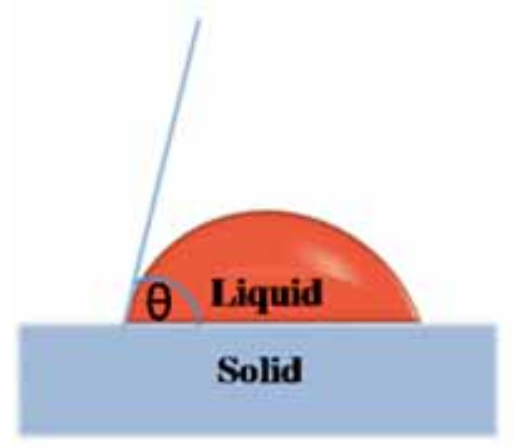

(a) Young's Model

$$
\cos \theta=(\gamma s v-\gamma s l) / \gamma l v
$$

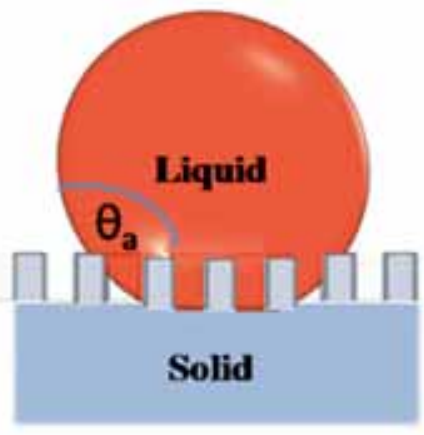

(b) Wenzel Model $\cos \theta_{\mathrm{a}}=\mathrm{r} \cdot \cos \theta \mathrm{b}$

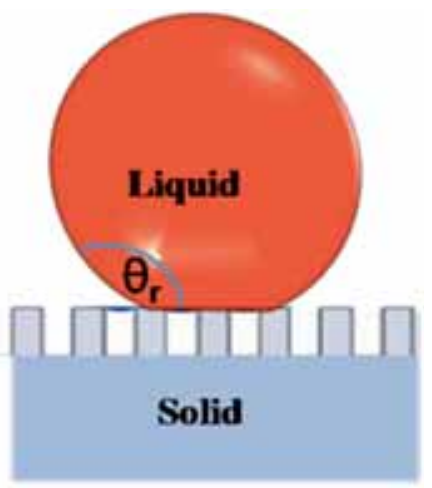

(c) Cassie Model $\cos \theta_{r}=f_{1} \cos \theta-f_{2}$

Figure 4. Young's, Wenzel and Cassie-Baxter models for hydrophobicity of solid surfaces.

The bar diagram representation of the variation in CA of undiluted EDTA-WB on different substrates before and after $\mathrm{ZnO}$ nanowires coating is shown in figure $3 \mathrm{e}$.

\subsection{Variation in CA with blood dilution}

Figure 5 shows the variation in the CA measured with different blood dilution ratios on $\mathrm{ZnO}$-coated samples of Quartz and PDMS, respectively. The dilution of blood with distilled water is in the ratio of $1: 25,1: 50$ and $1: 100$, respectively. The CA measurement is one of the important methods for analysing the surface properties in which the angle formed by the liquid drop on the surface of solid is measured. CA mainly depends upon the top molecular layers of solid and their properties. It is mostly used for characterizing the effect of adsorption of various films or other surface treatments on a solid surface in terms of surface energy change [19]. It also gives information related to the wetting properties of surface materials used for different devices/implants. The CA depends upon the adhesive forces between the liquid and solid formed by their molecular interactions. So, if the liquid interaction with solid surface increases, it will support lower CA and vice versa.

In various studies, $\mathrm{ZnO}$ nanowires are used as coating material because $\mathrm{ZnO}$ exhibits higher antibacterial properties as compared to other metal oxides nanostructures [13]. The available reports show that $\mathrm{ZnO}$ is not only suitable to kill bacteria with irradiation of UV light, but it can also inhibit bacterial growth under normal visible light [20]. Whang et al [23] showed the UV photoactive property of $\mathrm{ZnO}$, which is responsible for its antibacterial activity

$$
\begin{aligned}
& \mathrm{ZnO}+h v \rightarrow \mathrm{e}^{-}+\mathrm{h}^{+}, \\
& \mathrm{h}^{+}+\mathrm{OH}^{-} \rightarrow \bullet \mathrm{OH}, \\
& \mathrm{e}^{-}+\mathrm{O}_{2} \rightarrow \mathrm{O}_{2 \bullet}^{-}, \\
& \mathrm{O}_{2}^{-}+2 \mathrm{H}^{+}+\mathrm{e}^{-} \rightarrow \mathrm{H}_{2} \mathrm{O}_{2} .
\end{aligned}
$$

When $\mathrm{ZnO}$ is irradiated with UV light having wavelength smaller than the band gap of $\mathrm{ZnO}$, on the surface of semiconductor material, i.e., $\mathrm{ZnO}$, electron-hole generated as shown 


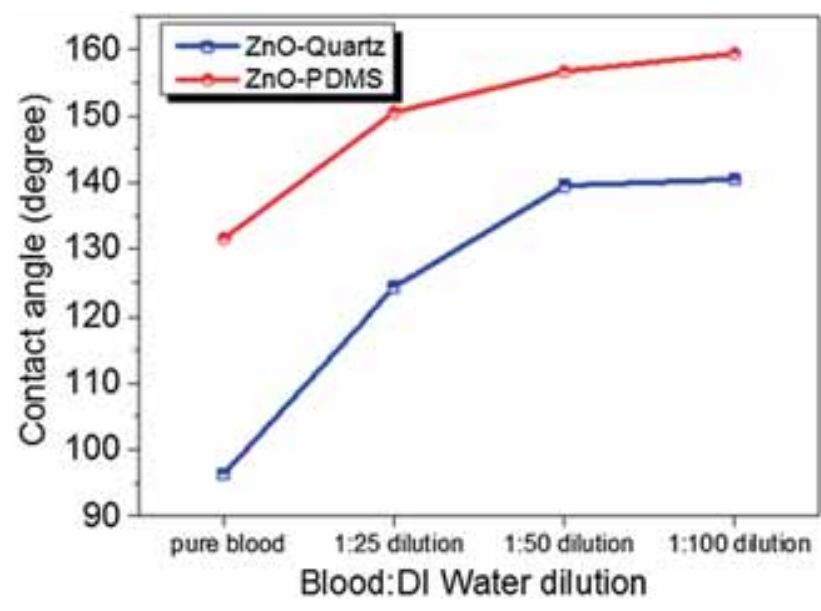

Figure 5. Variations in contact angle with dilution of whole blood on quartz and PDMS samples.

in equation (4). The generated holes may react with surface hydroxyls or water $\left(\mathrm{OH}^{-} / \mathrm{H}_{2} \mathrm{O}\right)$ to produce hydroxyl radicals $(\bullet \mathrm{OH})$ on the surface (equation (5)). Conduction band electrons react with molecular $\mathrm{O}_{2}$ adsorbed on the surface to generate $\left(\mathrm{O}_{2} \bullet\right.$ ) super-oxide radical (equation (6)). Finally, the radicals $\left(\bullet \mathrm{OH}\right.$ and $\mathrm{O}_{2} \bullet$ ) react with the bacterial cells to destroy and shrink them [21-23]. Along with antibacterial property, the $\mathrm{ZnO}$ water wetting properties can also be modified [24-26]. In few literature reports, we have found that it is possible to make $\mathrm{ZnO}$ as superhydrophobic without using any chemical treatment, by just storing in dark for about 40 days. We have utilized the antibacterial hydrophobic property of $\mathrm{ZnO}$ nanowires and successfully prepared various hydrophobic substrates with the help of $\mathrm{ZnO}$ nanowires. Our study suggests, if we use superhydrophobic $\mathrm{ZnO}$ nanowires coating, then, we can achieve a dual purpose. Along with the antibacterial activity of $\mathrm{ZnO}$, we can also achieve a hydrophobic property. To use the hydrophobic and antibacterial property of $\mathrm{ZnO}$, it is very easy to coat nanostructures on different materials' surfaces like glass, quartz, silicon and PDMS, which are widely used for many biomedical applications. The $\mathrm{ZnO}$ deposition by using drop-coating method (explained in experimental section) is very helpful to avoid the barrier of low heat resistance of many biomaterials, mainly polymers.

\section{Conclusions}

With the advancement of nanotechnology at a rapid rate, nanomaterials are playing important role in the development of biomaterials. For these advancements, the surfaces with special wettability properties have attracted the researchers for practical and fundamental research applications. In this study, we focussed on blood wettability including hydrophobic surfaces induced by biocompatible and safe nanoparticles of $\mathrm{ZnO}$. Surface modification of various types of substrates by a biocompatible $\mathrm{ZnO}$ material is demonstrated. The nanowirelike morphology of $\mathrm{ZnO}$ nanostructures is used for changing the CA on various types of substrates. The results reveal that $\mathrm{ZnO}$ nanowires coating is suitable for hydrophobization of various type of substrates, which are showing hydrophilic nature for EDTA-WB. These studies help in evaluating the wetting behaviour of biomaterial for EDTA-WB for various applications in medical sciences, like in the field of biosensors, transducers, corrosion resistance, liquid transportation, micro-fluidic systems and bio-engineering.

\section{Acknowledgements}

We kindly acknowledge Department of Technical Education, Government of Haryana and Department of Biomedical Engineering, D.C.R. University of Science \& Technology, Sonipat, India for the support.

\section{References}

[1] Tathe A, Ghodke M and Nikalje A P 2010 Int. J. Pharm. Pharm. Sci. 219

[2] Khorasani M T and Mirzadeh H 2004 J. Appl. Polym. Sci. 91 2042

[3] Lin H, Ding L, Deng W, Wang X, Long J and Lin Q 2013 Adv. Chem. Eng. Sci. 3236

[4] Zhou J, Xu N and Wang Z L 2006 Adv. Mater. 182432

[5] Bhavsar K, Ross D, Prabhu R and Pollard P 2015 Nano Rev. 6 26711

[6] Willander M and Nur O 2011 Proc. SPIE 803189

[7] Li Z, Yang R, Yu M, Bai F, Li C and Wang Z L 2008 J. Phys. Chem. C 11220114

[8] Lakshmi S, Pradeep S S and Kumar J A 2002 J. Biomed. Mater. Res. 6126

[9] Vergidis P and Patel R 2012 Infect. Dis. Clin. North Am. 26 173

[10] Jones D S, McGovern J G and Woolfson D A 1997 Biomaterials 18503

[11] Balazs D J, Triandafillu K and Chevolot Y 2003 Surf. Interface Anal. 35301

[12] Zdanowski Z, Koul B and Hallberg E 1997 J. Biomater. Sci. Polym. Ed. 8825

[13] Tam K H, Djurisic A B, Chan C M N and Leung Y H 2008 Thin Solid Films $\mathbf{5 1 6} 6167$

[14] Yakimova R, Selegard L, Khranovsky V, Pearce R, Lloyd A and Spetz et al 2012 Front. Biosci. (Elite Ed.) 4254

[15] Wang S and Jiang L 2007 Adv. Mater. 193423

[16] Young T 1805 Phil. Trans. R Soc. London 9565

[17] Wenzel R N 1936 Ind. Eng. Chem. 28988

[18] Cassie A B D and Baxter S 1944 Trans. Faraday Soc. 40546

[19] Oliva M H, Morenob A M G, Cano A R, Bruque J M and Martinb M L G 2015 Annales UMCS, Chemia 701

[20] Jones N, Ray B, Ranjit K T and Manna A C 2008 FEMS Microbiol. Lett. 27971

[21] Ho W K, Yu J C and Lee S C 2007 Appl. Catal. B 73135 
[22] Lin H X, Xu Z T and Wang X X 2008 J. Biomed. Mater. Res. 87425

[23] Whang T J, Hsieh M T and Chen H H 2011 Appl. Surf. Sci. 2582796

[24] Bhushan B and Jung Y C 2011 Prog. Mater. Sci. 561
[25] Zhang Y, Chen Y, Shi L, Li J and Guo Z 2012 J. Mater. Chem. 22799

[26] Yang S, Jin X, Liu K and Jiang L 2013 Particuology 11 361

[27] Nakajima A 2011 NPG Asia Mater. 349 